\title{
Towards a conceptual framework of direct and indirect environmental effects of co-working
}

\author{
Bhavana Vaddadi \\ Integrated Transport Research Lab \\ KTH Royal Institute of Technology \\ Stockholm, Sweden \\ bhavana@kth.se \\ Jan Bieser \\ Department of Informatics \\ University of Zurich \\ Zurich, Switzerland \\ jan.bieser@ifi.uzh.ch
}

\author{
Johanna Pohl \\ Center for Technology and Society \\ TU Berlin \\ Berlin, Germany \\ pohl@ztg.tu-berlin.de \\ Anna Kramers \\ Department of Strategic Sustainability Studies \\ KTH Royal Institute of Technology \\ Stockholm, Sweden \\ kramers@kth.se
}

\begin{abstract}
Through virtual presence, information and communication technology (ICT) allows employees to work from places other than their employer's office and reduce commuting-related environmental effects (telecommuting). Working from a local coworking space, as a form of telecommuting, has the potential to significantly reduce commuting and is not associated with deficits of working from home (e.g. isolation, lack of focus). However, environmental burden might increase through co-working due to the infrastructure required to set-up and operate the co-working space and potential rebound effects. In this paper, we (1) develop a framework of direct and indirect environmental effects of coworking based on a well-known conceptual framework of environmental effects of ICT and, (2) apply the framework to investigate the case of a co-working living lab established in Stockholm. Based on interviews and surveys conducted with coworkers in the living lab and infrastructure data of the co-working space, we roughly estimate associated energy impacts. Results show that energy requirements associated with operating the coworking space can counterbalance commute-related energy savings. Thus, in order to realize energy savings co-working should be accompanied with additional energy saving measures such as a net reduction of (heated) floor space (at the co-working space, at the employer's office and the co-workers home) and use of energyefficient transport modes.
\end{abstract}

\footnotetext{
$\leftarrow$ Bhavana Vaddadi, Integrated Transport Research Lab, KTH Royal Institute of Technology, Drottning Kristinas väg 40, 11428, Stockholm, Sweden. Permission to make digital or hard copies of all or part of this work for personal or classroom use is granted without fee provided that copies are not made or distributed for profit or commercial advantage and that copies bear this notice and the full citation on the first page. Copyrights for components of this work owned by others than ACM must be honored. Abstracting with credit is permitted. To copy otherwise, or republish, to post on servers or to redistribute to lists, requires prior specific permission and/or a fee. Request permissions from Permissions@acm.org. ICT4S2020, June 21-26, 2020, Bristol, United Kingdom

C 2020 Association for Computing Machinery. ACM ISBN 978-1-4503-75955/20/06...\$15.00 https://doi.org/10.1145/3401335.3401619
}

\section{CCS CONCEPTS}

-Social and professional topics $\sim$ Professional topics $\sim$ Computing and business $\sim$ Computer supported cooperative work $\bullet$ Applied computing $\sim$ Physical sciences and engineering Earth and atmospheric sciences $\sim$ Environmental sciences •Applied computing Physical sciences and engineering $\sim$ Telecommunications

\section{KEYWORDS}

ICT, co-working, telecommuting, energy consumption, commuting, flexible workplace

\section{ACM Reference format:}

Bhavana Vaddadi, Jan Bieser, Johanna Pohl and Anna Kramers. 2020. Towards a conceptual framework of direct and indirect environmental effects of co-working. In Proceedings of ICT4S $2020-7^{\text {th }}$ International Conference on ICT for Sustainability. ACM, Bristol, UK, 9 pages. https://doi.org/10.1145/3401335.3401619

\section{INTRODUCTION}

As cities continue to expand, people have started to move further away from city centers due to housing shortages and everincreasing rents making commuting a physical and mental burden. Due to an often unreliable transportation system and heavy dependence on private vehicles, millions of people spend long hours commuting to and from work [1].

In 2011 , roughly $38 \%$ of commuters in Stockholm were using private vehicles to commute to and from work while $25 \%$ used public transport [2]. In addition, car ownership and vehicular travel is ever increasing [3]. Besides its environmental impacts, commuting causes congestion during peak hours and has significant effects on individuals' well-being [4]. Hence, there is a dire need to adopt sustainable travel practices.

Information and communication technology (ICT) has transformed our existing patterns of production and consumption 
with consequences for the environment [5], [6] [7], [8]. Telecommuting, working remotely and collaborating with colleagues and partners by means of ICT, has the potential to reduce commute-related environmental impacts. A specific case of telecommuting centers are co-working (CW) spaces. $\mathrm{CW}$ "describes any situation where two or more people are working in the same place together, but not for the same company" [9, p. 3]. CW spaces are "shared workplaces utilized by different sorts of knowledge professionals [...] working in various degrees of specialization in the vast domain of the knowledge industry" [10, p.194]. CW holds the potential to significantly reduce environmental impacts associated with commuting and is not associated with deficits of working from home (e.g. isolation, lack of focus). In order to realize these benefits, the choice of location of the CW space is in particular critical [11], [12],[13]

However, CW can also increase environmental burdens, for example through required infrastructure to set-up and operate the CW space. It can also lead to rebound effects, if employees spend time and money saved on commuting on other activities, goods and services that are associated with environmental impacts [14]. In order to draw more specific conclusions about whether $\mathrm{CW}$ can contribute to an overall reduction in resource consumption, and which factors are particularly relevant, a more precise analysis is necessary [11], [15], [16], [17]

One approach that has gained momentum in sustainability research is to test potentially sustainable innovations in living labs [18]. In living labs, data can be collected in a real-life setting and later be used for environmental assessment [19]. Within Mistra SAMS, a research project on sustainable transport in Sweden, a living lab CW space has been set up in the south of Stockholm (in the suburb Tullinge) and is in operation since January 2019. As of February 2020, out of 60 recruited participants, about 44 employees who live close to the $\mathrm{CW}$ space regularly work from there and can potentially avoid lengthy commutes to their employers' offices.

In this paper, we (1) develop a conceptual framework of the diverse environmental impacts of CW, and (2) apply the framework to investigate environmental impacts associated with the CW living lab in Stockholm. Thereby, we provide a systematic overview of potential positive and negative environmental impacts of CW. We hope this can provide first insights on environmental impacts of $\mathrm{CW}$ and stimulate further research on $\mathrm{CW}$ and other promising ICT applications, which is required to harness the potential to avoid environmental burdens and mitigate negative impacts of increasing ICT use.

The paper is organized as follows: Materials and methods are described in Section 2. The conceptual framework of environmental effects of CW is presented in Section 3, followed by the application of the framework to the CW case in Stockholm in Section 4 . We end with a discussion and conclusion and identify potential for future research in Section 5 .

\section{MATERIAL AND METHODS}

To develop a conceptual framework reflecting the environmental effects of $\mathrm{CW}$, we use the framework of environmental effects of ICT by Hilty and Aebischer [8] and adapt it to the specific case of
CW. The well-known and frequently applied taxonomy of environmental effects of ICT was introduced by Berkhout and Hertin [6] at first and has been revised several times since then [8], [16], [17]. The framework distinguishes three layers of environmental effects of ICT:

1. Direct environmental effects through production, use and disposal of ICT

2. Enabling effects of ICT use through the application of ICT also in other sectors (the effects result from changes in production and consumption patterns)

3. Systemic impacts through ICT-induced changes of existing socio-economic structures and institutions

This framework is useful to investigate the specific case of CW for the following reasons:

- $\mathrm{CW}$ is a specific use case of ICT as explained in the introduction.

- $\mathrm{CW}$ requires production, operation and disposal of infrastructures (e.g. CW space, ICT equipment), processes which cause environmental impacts (layer 1).

- $\quad \mathrm{CW}$ can change existing production and consumption patterns (e.g. avoiding work-related travel or changing collaboration methods among colleagues - layer 2).

- $\quad \mathrm{CW}$ can fundamentally affect the nature and location of work as well as transport habits at a societal level if it is adopted at a larger scale (e.g. through diminishing of central business districts - layer 3).

To adapt the framework, we applied the universally defined environmental effects of ICT to the specific case of CW [8], [16].

In a second step, we apply the framework to roughly estimate energy impacts associated with the CW living lab in Stockholm. Wherever possible we use actual data collected in the CW living lab.

We (1) collected technical data of the CW space, such as floor space and equipment used, (2) interviewed participants on their everyday life, travel and work patterns, and, (3) collected daily time-use data (time spent on 'travel', 'work', 'everyday chores' and 'leisure'; use of transport modes) for three succeeding weeks by asking participants to fill out time-use diaries.

Data collection took place from September until November 2019. As the living lab is still in operation and data collection is still ongoing, we cannot estimate some effects and in some cases have to use publicly available statistics or make reasonable assumptions.

\section{CONCEPTUAL FRAMEWORK OF ENVIRONMENTAL EFFECTS OF CO- WORKING}

The framework, which describes direct, indirect and systemic environmental effects of CW, is shown in Fig. 1. The first layer, "Technology: Co-working infrastructure", describes the environmental effects of building, operating and maintaining 
Towards a conceptual framework of direct and indirect environmental effects of co-working

infrastructures required for $\mathrm{CW}$ (e.g. $\mathrm{CW}$ space, video conferencing systems, parking places, etc.).

the employer. Such a transformation includes changes to working cultures, ways of communication, lifestyles or land use patterns,

\section{Decrease of resource use Increase of resource use}

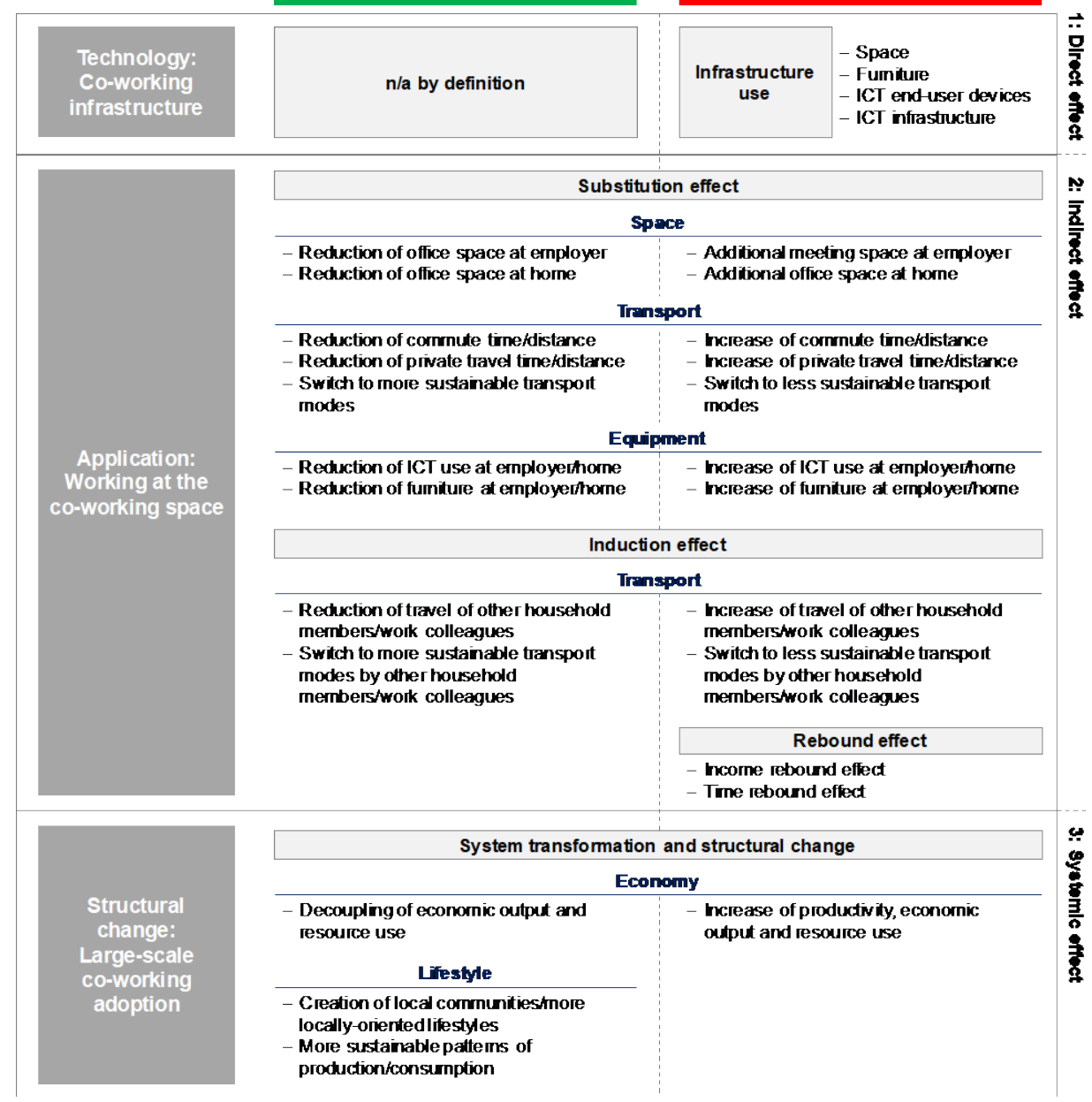

Figure 1: Framework of environmental effects of co-working (based on [8] and [16]).

The second layer, "Application: Working at the co-working space", describes the environmental effects due to individual coworkers or organizations adopting to working at the $\mathrm{CW}$ space instead of the employer's office or from home. This directly affects the use of office space, transport infrastructure, and ICT equipment. In addition, behavioral changes, due to changing work and travel practices are possible. For example, employees might spend money and time not spent on commuting on other activities that are associated with their own environmental impacts (patterns known as income and time rebound effects) [20], [21].

The third layer, "Structural change: Large-scale co-working adoption", describes the environmental effects of a system transformation towards $\mathrm{CW}$. It leaves the level of individual coworkers or organizations and focuses on environmental consequences of a transformation towards a society-wide $\mathrm{CW}$ culture. This means that factors such as place of residence are decisive for the place of work, regardless of the actual location of which only occur if a critical mass of society switches from conventional working habits to $\mathrm{CW}$.

In the following, we describe each layer in some detail. In the framework, we included effects described in literature and observed during operation of the CW living lab. Still, effects beyond the ones we describe can exist.

\subsection{Technology layer}

Direct environmental effects of building, operating and maintaining $\mathrm{CW}$ spaces are by definition unfavorable environmental effects as they all require resources, energy and cause emissions, but do not avoid anything yet. Main environmental impacts associated with building and operating a $\mathrm{CW}$ space are caused by facilities (main offices, auxiliary rooms, parking) and equipment (ICT end-user devices and infrastructure, office furniture) (Table 1).

Environmental impacts caused throughout the life cycle of facilities and equipment are caused by the construction of facilities 
and production of equipment (production phase), the operation of these (use phase) and processes at their end-of-life (EoL phase). As for the production phase, the construction of $\mathrm{CW}$ spaces and production of ICT equipment, furniture and other required equipment cause environmental impacts.

With regard to facilities, energy consumption during the operational phase is of great relevance [22] and can be divided into energy for heating, cooling and lighting. Use phase energy demand in office buildings can be estimated proportional to office space [23]. With increasing adoption of energy-efficient building technologies (e.g. improved insulations) the relative importance of the construction phase increases.

With regard to ICT end-user devices, the relevance of the production phase depends on the type of the device, the service life and energy efficiency of the devices. The smaller and more energy efficient the devices, the more important is the production phase [24].

With regard to ICT infrastructure, communication infrastructure (e.g. networks) as well as servers (or data centers) are most relevant. Overall, the total number of equipment used, their production impacts and their energy consumption during operation is decisive for the total environmental impacts.

The main target on this layer is to reduce the relative effects per co-worker that stem from constructing, operating, and maintaining $\mathrm{CW}$ facilities and equipment. Amongst others, this means to minimize required $\mathrm{CW}$ office space and to aim for high occupancy rates.

\subsection{Application layer}

The environmental effects resulting from running and using the $\mathrm{CW}$ space can work in both directions - reducing and increasing resource use. Main environmental impacts of $\mathrm{CW}$ are caused by changes to the process/use of space, transport and office equipment. The main drivers of environmental impacts on this layer are changes to the floor space at the employer's office and the reduction of commuting.

As discussed in the introduction, $\mathrm{CW}$ spaces that are close to the employees' homes can contribute to a reduction in commute time and distance. This is the case, if trips to the $\mathrm{CW}$ space replace commute trips to work. If working from the $\mathrm{CW}$ space replaces working from home, commute time and commute distance increase instead.

Table 1: Facilities and equipment in the co-working space.

\begin{tabular}{|l|l|l|}
\hline \multirow{4}{*}{ Facilities } & Main use area & $\begin{array}{l}\text { - Workplaces } \\
\text { - Meeting rooms } \\
\text { - Telephone rooms } \\
\text { - Event space }\end{array}$ \\
\cline { 2 - 3 } & Auxiliary areas & $\begin{array}{l}\text { - Kitchen } \\
\text { - Bathrooms } \\
\text { - Parking space }\end{array}$ \\
\hline \multirow{2}{*}{ Equipment } & $\begin{array}{l}\text { ICT end-user } \\
\text { devices and } \\
\text { infrastructure }\end{array}$ & $\begin{array}{l}\text { End-user devices (screens, } \\
\text { printers, white boards) } \\
\text { Infrastructure (e.g. network, } \\
\text { servers) }\end{array}$ \\
\hline
\end{tabular}

\begin{tabular}{|l|l|l|}
\hline & $\bullet$ Conferencing equipment \\
\cline { 2 - 3 } & Office furniture & $\begin{array}{l}\bullet \text { Desks } \\
\bullet \text { Chairs }\end{array}$ \\
\cline { 2 - 3 } & \multirow{2}{*}{ Other } & $\begin{array}{l}\bullet \text { Coffee machine } \\
\bullet\end{array}$ \\
\hline
\end{tabular}

If, before the adoption of $\mathrm{CW}$, private activities such as library visits, meeting friends or shopping had been combined with commute trips, CW can also induce additional trips. Further, changes in commuting can lead to a change in transport modes used (modal split). For example, for shorter commutes people might consider taking the bike instead of the car. However, people might also increase their use of cars for shorter commute trips, because the opportunity cost of taking the car instead of public transport are less significant (in public transport people can do other activities).

Working from $\mathrm{CW}$ spaces has the potential for a reduction of office space at the employer's office and the employee's home (e.g. by implementing desk sharing at the employer's office). However, if these office spaces are not sufficiently reduced, $\mathrm{CW}$ can have a net increasing effect on office space due to the $\mathrm{CW}$ space. Also, CW might increase demand for meeting space at the employer's office, which is required to communicate with co-workers. Employers adopting $\mathrm{CW}$ might also require additional ICT equipment (e.g. for video conferencing).

Furthermore, the saved travel costs can be used for other purposes (income rebound effects) and thus contribute to an increased use of resources [15]. Finally, co-workers can spend saved commute time on other activities that are associated with environmental impacts (time rebound effects [14]).

The main target on this layer is to promote desired and mitigate undesired effects. The effect of $\mathrm{CW}$ on (heated) floor space (at the employer and at the co-worker's home), the average change in commute distance of co-workers, thus, the location of the $\mathrm{CW}$ space (central, sub-urban, close to the co-workers houses), and the transport modes used, seem to be the most important drivers of the environmental impacts on the application layer.

\subsection{Structural change layer}

Structural effects of $\mathrm{CW}$ are effects that occur if $\mathrm{CW}$ is adopted at a larger scale. For example, given that $\mathrm{CW}$ reduces time spent commuting and adds flexibility to time and place of work, it may influence families' decisions regarding where to live, jobs, and investments in their dwellings [25], [26]. In the long-term this can also change land-use patterns, e.g. towards "more decentralized and lower-density land use patterns" [27, p. 12]. CW from local CW spaces at a larger scale can also change the nature of work and would reduce demand for major office buildings in business districts, which then could be used for other purposes. Finally, CW can also change traffic streams and demand for transport in general.

Rebound effects occur also on the structural layer. For example, if $\mathrm{CW}$ increases the productivity of an industry and stimulates growth; this can lead to an increase in resource consumption and emissions (economy-wide rebound effect) [15], [28]. 
Towards a conceptual framework of direct and indirect environmental effects of co-working

Structural effects of CW depend on many variables in the broader societal and economic system and are therefore difficult to predict. A long-term CW strategy at a larger scale needs to identify potential structural effects and promote $\mathrm{CW}$ schemes that foster environmentally favorable structural effects and mitigate unfavorable ones.

\section{CASE STUDY: ENVIRONMENTAL EFFECTS OF A CO-WORKING SPACE IN STOCKHOLM}

\subsection{Introduction to the co-working space in Stockholm}

Situated in Tullinge, a suburb in the south of Stockholm, the CW space is an experimental living lab set up to observe a wide range of effects of having a workplace close to the home of the participants. The $\mathrm{CW}$ space integrates various accessibility and mobility services to participants that allow them to book, plan, and travel. It offers an activity-based workplace close to co-workers' homes, gives access to 3 electric bikes ( 2 electric bicycles and 1 electric cargo bicycle) for free and a peer-to-peer carpooling scheme.

It is equipped with 14 workplaces, which can be booked via an online application, a well-equipped conference room for eight people, as well as three rooms for telephone or video calls. This experimental $\mathrm{CW}$ space acts as a platform to bring together a range of actors such as citizens, researchers, business and public authorities to create, validate, and test new mobility and accessibility technologies and services in a real-life context. The CW space has been in operation since January 2019 and as of February 202044 out of 60 participants regularly work there.

\subsection{Co-working impacts on time-use and travel}

We used the results of the time-use diaries of 20 co-workers who work for an IT company in Kista, north of Stockholm to compare their daily time-use including travel. Because living close to the CW space in the south of Stockholm was a requirement for participating, these co-workers significantly reduced their commute time and distance on $\mathrm{CW}$ days compared to employer office days. We compare time spent on 'travel', 'work', 'everyday chores' and 'leisure' on days, when people work from the employer's office, from the CW space or from home (Fig. 2).

We also compared the (share of) time people spent in different transport modes on these days (Fig. 3). We did not consider days, when people worked from other locations or from several locations on one day. We also excluded low quality data entries and untypical work days (work time lower than $4 \mathrm{~h}$; total recorded time lower than $8 \mathrm{~h}$; time difference between the recorded time spent on 'travel' and recorded time in specific transport modes is higher than $100 \mathrm{~min}$; these were two separate questions). This results in time-use data from 244 workdays.

\subsubsection{Time spent on activities}

ICT4S2020, June 21-26, 2020, Bristol, United Kingdom

Of all diary days, $56 \%$ are employer office days, $17 \% \mathrm{CW}$ days, $12 \%$ home office days and $15 \%$ other types of workdays (e.g. various work locations).

Average 'travel' time is highest, when people work from the employer's office (133 $\mathrm{min}$ ) and decreases by $68 \mathrm{~min}$ on CW days and $104 \mathrm{~min}$ on home office days. Average working time is also slightly higher on days, when people work from the employer's office (523 $\mathrm{min}$ ) and marginally lower on home office (-6 min) and $\mathrm{CW}$ days (-14 $\mathrm{min})$. One possible explanation for slight differences in work time is that on home office or $\mathrm{CW}$ days employees spend less time socializing with work colleagues who are not physically present.

Average time spent on 'everyday chores' and 'leisure' is highest on home office days and lower on days when people work from the employer's office or the CW space. Differences in time spent on other activities (e.g. sleep) are also possible, but were not collected in the time-use diaries.

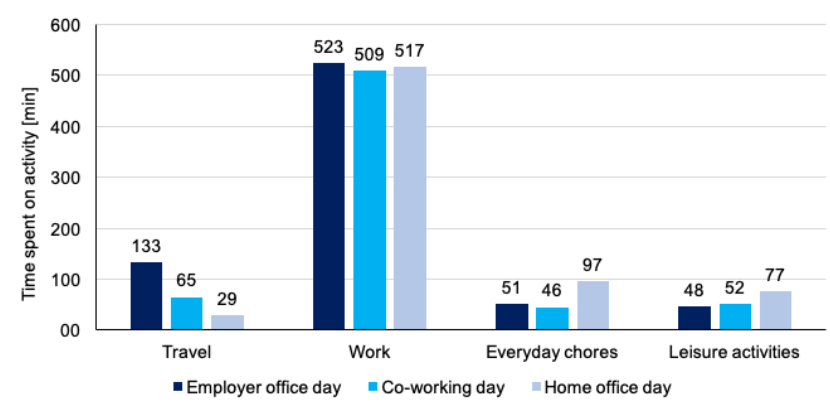

Figure 2: Average time spent on an activity by work location on that day.

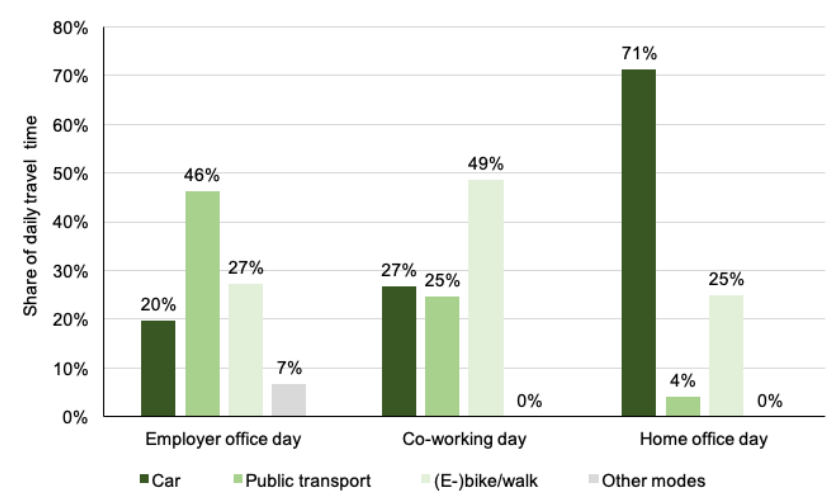




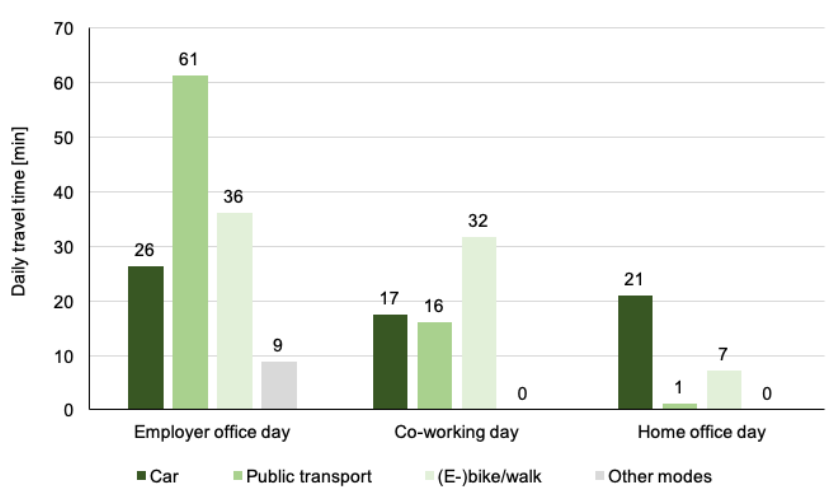

Figure 3: Average share of travel time (top) and average absolute time (bottom) spent in different transport modes by work location on that day (other modes are for example boats).

\subsubsection{Used transport modes (modal split)}

On employer office days, average time spent in public transport is highest (61 min) and significantly lower on CW days (16 min) and is close to zero on home office days.

Average time spent travelling by car is also highest on employer office days (26 min) and slightly lower on CW days (17 min). Interestingly, on home office days, co-workers spend on average more time in car transport $(21 \mathrm{~min})$ than on $\mathrm{CW}$ days. One explanation for this could be that individuals shift activities which induce car transport to home office days (e.g. going shopping)

Average time spent (e-) biking and walking is of the same order of magnitude on employer office and $\mathrm{CW}$ days and significantly lower on home office days.

In the interviews, we asked participants about their commute transport modes specifically. The results indicate that public transport is the preferred commute transport mode, followed by car transport. This confirms the patterns observed in the time-use data.

Interviews also showed that biking and walking is rather done for private purposes. This is one possible explanation why no large differences in average time spent on biking or walking can be observed between employer office and CW days; however, on home office days, average time spent biking or walking is comparatively low. This could indicate, that that bike or foot travel is somehow related to work routines outside the home (potentially due to walking or biking between home, public transport stops and the office). Thus, further research is required to investigate this relationship.

\subsection{Energy impacts}

In the following we apply the framework of environmental effects of $\mathrm{CW}$ to roughly estimate energy impacts of the CW living lab.

\subsubsection{Estimation approach}

We estimate energy requirements associated with...

- heating, cooling and lighting of the $\mathrm{CW}$ space (direct effect),
- ICT equipment operated in the $\mathrm{CW}$ space (direct effect), and,

- $\quad$ changes in travel time (indirect effect), on employer office, CW and home office days.

Due to lack of data, we do not consider furniture or changes in space use at home or the employer office; neither effects on behavior of other household members or work colleagues (e.g. changes in travel) nor systemic effects. To some extent, changes in travel time include income and time rebound effect, as people spend saved commuting cost and time on travel for other purposes.

All calculations are performed for one $\mathrm{CW}$ day of one coworker. Calculations focus on the use phase (energy requirements associated with the operation of the $\mathrm{CW}$ space and fuel consumption for transport). Energy impacts associated with production of goods and services (e.g. production of cars, construction of office buildings, and production of ICT equipment) are out of scope.

\subsubsection{Inventory data.}

Table 2 provides an overview of data on floor area, ICT equipment and the number of people working in the $\mathrm{CW}$ space.

To estimate energy impacts of heating, cooling and lighting of office space we used the floor space of the CW space and yearly energy requirements of standard office buildings according to the "Institut Wohnen und Umwelt" [23],[29]. We divided energy impacts of heating, cooling and lighting of office space by the number of people working in the $\mathrm{CW}$ space and the number of workdays per year to estimate impacts per co-worker and CW day. Thereby, we assume that co-workers who work for other companies have the same $\mathrm{CW}$ patterns (number of $\mathrm{CW}$ days) as the co-workers working for the IT Company in Kista.

For operation of ICT equipment, we used the number of devices in operation in the $\mathrm{CW}$ space and daily device energy requirements according to ecoinvent [30]. To estimate impacts per co-worker and $\mathrm{CW}$ day, we divided ICT equipment energy consumption by the number of workplaces at the $\mathrm{CW}$ space. We did not include network devices and one videoconferencing system due to lack of data.

To estimate energy impacts of changes in travel time, we used the results of the time-use diaries (Fig. 2, Fig. 3), direct energy requirements of fuel consumption and provisioning of travel modes according to mobitool [31] and average speed of transport modes [32]. We needed to estimate the distances driving with each transport mode using average speed of transport modes, because in the travel diaries co-workers recorded the time spent in transport modes.

\subsubsection{Estimation results.}

Fig. 4 shows the estimated average difference in energy consumption between one person working from the $\mathrm{CW}$ space for one day, the employer's office or home. It shows that much energy consumption is caused by heating, cooling and lighting (mainly heating and lighting, only few cooling) of CW office space (24.0 $\mathrm{MJ}$ ) and only few energy consumptions is caused by operation of ICT equipment $(2.0 \mathrm{MJ})$. 
Towards a conceptual framework of direct and indirect environmental effects of co-working

Table 2: Co-working space floor area, amount of ICT equipment used in the co-working space and number of coworkers.

\begin{tabular}{|l|l|l|}
\hline Building & Floor area co-working space [m2] & 170 \\
\hline \multirow{4}{*}{$\begin{array}{l}\text { ICT } \\
\text { equipment }\end{array}$} & Number of workplaces & 14 \\
\cline { 2 - 3 } & Number of screens & 18 \\
\cline { 2 - 3 } & Number of desktop computers & 1 \\
\cline { 2 - 3 } & Number of printers & 1 \\
\cline { 2 - 3 } & Number of TV sets & 1 \\
\hline \multirow{3}{*}{ Co-workers } & $\begin{array}{l}\text { Number of co-workers regularly working in } \\
\text { the co-working space }\end{array}$ & 44 \\
\cline { 2 - 3 } & $\begin{array}{l}\text { Number of co-workers from IT-company in } \\
\text { Kista for whom time-use diaries are available }\end{array}$ & 20 \\
\hline
\end{tabular}

Compared to employer office days, average reduction in travel leads to a reduction of travel-related energy impacts of $22.5 \mathrm{MJ}$; thus, energy impacts of reduction in travel and energy required for heating, cooling and lighting of office space roughly cancel each other out. Compared to home office days, co-workers spend on average more time travelling on $\mathrm{CW}$ days; still travel-related energy consumption is slightly lower. This is because on home office days, people use the car on average more than on CW days. However, travel-related energy savings on $\mathrm{CW}$ days compared to home office days are much lower than the energy required to operate the $\mathrm{CW}$ space. The total energy required for heating, cooling and lighting the $\mathrm{CW}$ space does not increase proportionally with increasing utilization of the $\mathrm{CW}$ space. That is, because buildings do not require much more heating energy if occupancy increases or vice versa. However, the number of avoided employer office days (long commute) is proportional to total commuterelated energy savings (e.g. one $\mathrm{CW}$ or home office day avoids one long commute, two $\mathrm{CW}$ or home office days avoid two long commutes,...). Thus, substituting additional employer office days with $\mathrm{CW}$ or home office days is a good strategy to increase travelrelated energy savings.

When interpreting the results, we have to consider that this estimation did not consider changes in energy consumption at home or at the employer's office. It is plausible to assume a decrease in these energy requirements, leading to additional energy savings through CW. However, income and other rebound effects could compensate for the savings.

We also did not consider interdependencies between weekdays and weekends, because only few diarists carefully filled out timeuse diaries on weekends. In principle, $\mathrm{CW}$ can also impact time-use on weekends. For example, people could systematically shift activities for which they require the car (e.g. shopping) from weekends to home office days. This would reduce the car use on weekends, but total car use per week would not change.

\section{DISCUSSION AND CONCLUSION}

CW from a local CW space is a promising ICT use case to reduce transport demand and associated environmental impacts, while
ICT4S2020, June 21-26, 2020, Bristol, United Kingdom

having a positive effect on well-being of employees (e.g. more time for family and friends). However, $\mathrm{CW}$ also causes environmental impacts, for example through infrastructure required to operate $\mathrm{CW}$ spaces or through time rebound effects.

Based on an existing framework of environmental effects of ICT, we developed a conceptual framework of environmental effects of CW. The framework distinguishes environmental effects of CW on three layers: (1) direct effects through the infrastructure required to operate $\mathrm{CW}$ spaces, (2) indirect effects due to individual co-workers or organizations adopting $\mathrm{CW}$ (e.g. avoided commutes), and, (3) structural effects through a system transformation towards $\mathrm{CW}$ (e.g. fundamental changes in demand for transport and office space).

\section{Co-working space vs. employer office}

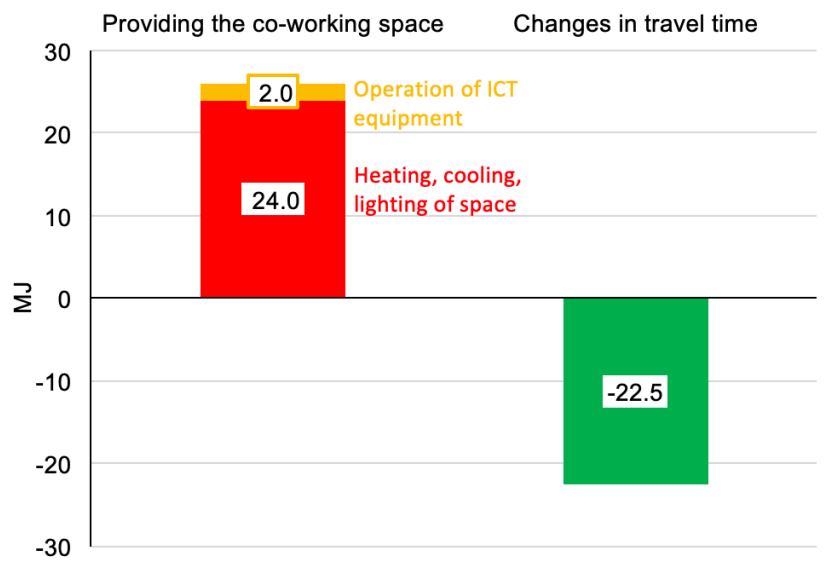

Co-working space vs. home office

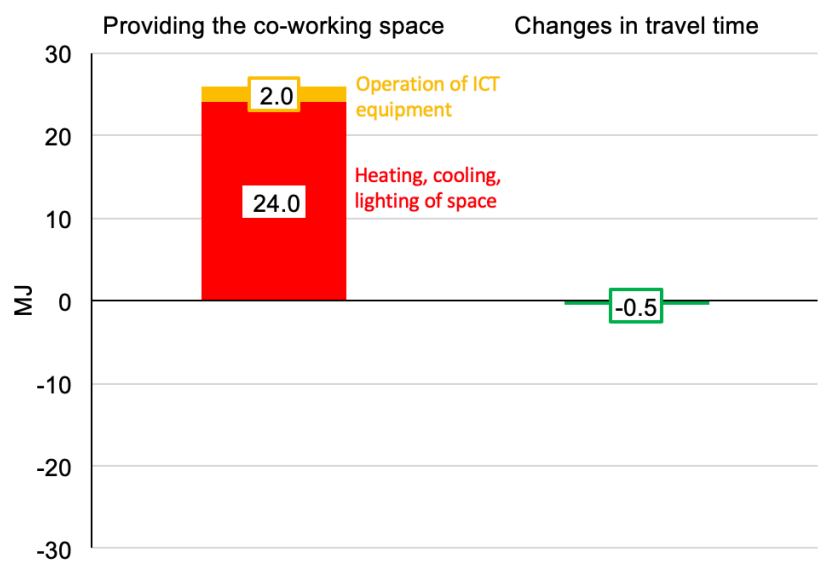

Figure 4: Difference in average energy requirements on a co-working day compared to a workday at the employers' office (top) or at home (bottom) across co-workers.

While direct effects are environmentally unfavorable by definition (they increase resource use), indirect effects and systemic effects can increase but also reduce resource use (e.g. by avoiding commute time or inducing additional travel for other 
purposes). Thus, net environmental effects depend on the magnitude of effects on all three layers and institutions should consider them when developing and adopting $\mathrm{CW}$ schemes.

In our case study of a CW living lab in Stockholm, we found that co-workers on average travelled most on employer office days, less on CW days and least when they worked from home, leading to travel-related energy savings. However, changes in travel mode can counterbalance this effect, as we found in our case study: On home office days, participants spent on average more time travelling by car than on CW days, leading to higher travel-related energy use on home office days than on CW days.

A rough estimation shows that the energy required to operate the $\mathrm{CW}$ space and travel-related energy savings roughly counterbalance each other on employer office and CW days. Thus, CW does not lead to energy savings per se, but should be accompanied by additional energy savings measures, such as reduction of office space at the employer's office. One way to reduce employer office space is to, instead of having fixed workplaces, adopt shared workplaces which can be booked by employees for days when they work from the employer's office. This can increase the utilization of workplaces at employer offices and allow for reduction of total office space; however, in companies with traditional work environments a transformation of working culture, tools and regulations as well as support for employees who struggle with such a change might be required. Other companies (e.g. start-ups) might not even rent or build larger office spaces and establish $\mathrm{CW}$ in the first place.

The main levers to realize energy savings through $\mathrm{CW}$ are a reduction of total travel time and distances (e.g. by choosing $\mathrm{CW}$ spaces close to home), use of sustainable transport modes, a net reduction of (heated) floor space (at the $\mathrm{CW}$ space, at the employer's office and the co-workers home) and a high number of $\mathrm{CW}$ or home office days (increasing the number of avoided commutes to employer offices).

Our calculations have limitations and uncertainties regarding the extent of daily activities captured, the energy requirements of travel and buildings, and the consideration of structural effects. We focused on operational energy requirements, thus environmental effects related to the production, construction and disposal of buildings, devices, vehicles and roads are not included in our estimation.

The co-workers investigated in this case study all work for the same IT Company. Thus, the possibility to adopt $\mathrm{CW}$ and behavioral changes of individuals through $\mathrm{CW}$ can be different for individuals working for different companies, in different sectors with different job requirements. Calculations are based on averages across all co-workers. Investigating individual co-workers can reveal further insights on changes in time-use patterns which depend on characteristics of individuals (e.g. preferred commute pattern). We also excluded weekends, because time-use diaries of weekends are of lower quality than of workdays. Thus, we could not assess associations between CW patterns, time use on weekends and total weekly travel.

Furthermore, we presented our results in terms of energy impacts of adopting CW. Environmental impacts beyond energy use (e.g. global warming potential or human toxicity) exist and need to be investigated to provide a full picture.

Finally, we did not collect time-use data of participants before they adopted $\mathrm{CW}$. Thus, whether $\mathrm{CW}$ leads to a net reduction in travel cannot be assessed with the available data. Still, the calculation demonstrates, that $\mathrm{CW}$ does not necessarily lead to energy savings and that non-travel related environmental impacts of CW matter.

Future research should take a broader perspective in terms of effects and activities included in the calculations and environmental impact categories and life cycle stages considered. If $\mathrm{CW}$ is adopted at a larger scale, systemic effects can lead to fundamental transformation of transport systems and land use. These effects are difficult to estimate and further research is required. We encourage companies and researchers to experiment with $\mathrm{CW}$ and find ways to use $\mathrm{CW}$ for reducing environmental effects of transport, work and everyday life. The framework developed in this paper and the findings of the living lab can provide guidance for this.

\section{ACKNOWLEDGMENTS}

This research is supported by the research program Sustainable Accessibility and Mobility Services - Mistra SAMS, funded by the Swedish Foundation for Strategic Environmental Research, Mistra, by the "Forschungskredit of the University of Zurich, grant no. FK19-014" and by the German Federal Ministry of Education and Research within the project "Digitalization and Sustainability". We also thank Hampus Mårtensson and Teo Enlund for their thoughts on an earlier version of this article.

\section{REFERENCES}

[1] Athena Lam. 2017. The Countries with the Longest and Shortest Commutes. Dalia. Retrieved December 17, 2019 from https://daliaresearch.com/blog/the-countries-with-the-longest-andshortest-commutes/.

[2] Transport Analysis. 2011. Commuting in Stockholm, Gothenburg and Malmö - a current state analysis (Summary Report 2011 )

[3] Patrick Moriarty and Damon Honnery. 2008. Low-mobility: The future of transport. Futures 40, 10: 865-872.

[4] Runing Ye and Helena Titheridge. 2015. Impact of Individuals' Commuting Trips on Subjective Well-being - Evidence from Xi' an, China. Journal of Transport \& Health 2, 2: S59.

[5] Anders Arvesen, Ryan Bright, and Edgar Hertwich. 2011. Considering only first-order effects? How simplifications lead to unrealistic technology optimism in climate change mitigation. Energy Policy 39, 11: 7448-7454.

[6] Frans Berkhout and Julia Hertin. 2004. De-materialising and rematerialising: Digital technologies and the environment. Futures 36, 8: 903-920.

[7] Jan Bieser and Lorenz Hilty. 2018. Assessing indirect environmental effects of information and communication technology (ICT): A systematic literature review. Sustainability (Switzerland) 10, 8: 1-19.

[8] Lorenz Hilty and Bernard Aebischer. 2015. ICT Innovations for Sustainability: An Emerging Research Field. In L.M. Hilty and B. Aebischer, eds., ICT Innovations for Sustainability. Springer International Publishing, 3-36.

[9] DTZ. 2015. The CoWorking Revolution.

[10] Alessandro Gandini. 2015. The rise of coworking spaces: A literature review. Ephemera-Theroy \& politics in organization 15, 1: 193-205.

[11] Anna Kramers, Mattias Hojer, Marcus Nyberg, and Malin Soderholm. 2015. Work hubs - location considerations and opportunities for reduced travel. In proceedings of EnviroInfo and ICT for Sustainability 2015, 126135.

[12] Tina Ringenson, Peter Arnfalk, and Anna Kramers. 2018. Indicators for Promising Accessibility and Mobility Services. Sustainability 10, 8: 1-19.

[13] Liridona Sopjani, Anna Kramers, and Peter Arnfalk. 2018. AaaS and MaaS for reduced environmental and climate impact of transport Creating 
Towards a conceptual framework of direct and indirect environmental effects of co-working

ICT4S2020, June 21-26, 2020, Bristol, United Kingdom

indicators to identify promising digital service innovations for. In proceedings of ICT4S 2018 - 5th International Conference on Information and Communication Technology for Sustainability, 137-152

[14] Jan Bieser and Lorenz Hilty. 2018. An Approach to Assess Indirect Environmental Effects of Digitalization Based on a Time-Use Perspective. Advances and New Trends in Environmental Informatics, 67-78.

[15] Miriam Börjesson Rivera, Cecilia Håkansson, Åsa Svenfelt, and Göran Finnveden. 2014. Including second order effects in environmental assessments of ICT. Environmental Modelling and Software 56: 105-115.

[16] Nathaniel Horner, Arman Shehabi, and Ines Azevedo. 2016. Known unknowns: Indirect energy effects of information and communication technology. Environmental Research Letters 11, 10

[17] Johanna Pohl, Lorenz Hilty, and Matthias Finkbeiner. 2019. How LCA contributes to the environmental assessment of higher order effects of ICT application: A review of different approaches. Journal of Cleaner Production 219: 698-712.

[18] Christa Liedtke, Carolin Baedeker, Marco Hasselkuß, Holger Rohn, and Viktor Grinewitschus. 2015. User-integrated innovation in Sustainable LivingLabs: An experimental infrastructure for researching and developing sustainable product service systems. Journal of Cleaner Production 97 106-116.

[19] Johanna Pohl, Paul Suski, Franziska Haucke, Felix Piontek, and Michael Jäger. 2018. Beyond Production - the Relevance of User Decision and Behaviour in LCA. In F. Teuteberg, M. Hempel, and L. Schebek, eds., In Progress in Life Cycle Assessment. Springer Berlin Heidelberg, 3-19.

[20] Jan Bieser and Lorenz Hilty. 2020. Conceptualizing the impact of information and communication technology on individual time and energy use. Telematics and Informatics 49, February: 101375.

[21] Steve Sorrell and John Dimitropoulos. 2008. The rebound effect: Microeconomic definitions, limitations and extensions. Ecological Economics 65, 3: 636-649.

[22] Jörn Krimmling and Ondřej Flanderka. 2017. Energiebedarf von Bürogebäuden Richtwerte und Einflussparameter für die Planung (Translated: Energy Requirements for Office Buildings: Benchmarks and Parameters influencing the planning). Fraunhofer IRB

[23] Jens Knissel. 2004. Energy efficient office buildings. Institut Wohnen und Umwelt October: 1-6.

[24] Roland Hischier, Vlad Coroama, Daniel Schien, and Mohammad Achachlouei. 2015. Grey Energy and Environmental Impacts of ICT Hardware. In L.M. Hilty and B. Aebischer, eds., In ICT Innovations for Sustainability. Springer International Publishing, 171-189.

[25] Ilan Salomon. 1986. Telecommunications and travel relationships: a review. Transportation Research Part A: General 20, 3: 223-238.

[26] Frank Schiff. 1983. Flexiplace: An idea whose time has come. IEEE Transactions on Engineering Management EM-30, 1: 26-30.

[27] Patricia Mokhtarian. 2009. If telecommunication is such a good substitute for travel, why does congestion continue to get worse? Transportation Letters 1, 1: 1-17.

[28] Jan Bieser and Lorenz Hilty. 2018. Indirect Effects of the Digital Transformation on Environmental Sustainability: Methodological Challenges in Assessing the Greenhouse Gas Abatement Potential of ICT. In proceedings of ICT4S 2018 - 5th International Conference on Information and Communication Technology for Sustainability, 68-53.

[29] EnWiPo. 2017. Energiebedarf von Bürogebäuden Ermitteln. Retrieved January 14, 2020 from https://www.enwipo.de/2017/03/07/energiebedarfvon-buerogebaeuden-ermitteln/.

[30] Rolf Frischknecht, Niels Jungbluth, Hans-jörg Althaus, et al. 2005. The ecoinvent Database: Overview and Methodological Framework. The International Journal of Life Cycle Assessment 10, 1: 3-9.

[31] Rolf Frischknecht, Annika Messmer, Philippe Stolz, and Matthias Tuchschmid. 2016. mobitool Grundlagenbericht Hintergrund, Methodik \& Emissionsfaktoren (Translated: mobitool basic report background, methodology \& emission factors)

[32] Leanne Johnson, Afzal Hossain, Kyle Thomson, and Warwick Jones. 2016 Trip characteristics of lengthy commutes. In BITRE Research Report 144 - Lengthy Commutes in Australia. Bureau of Infrastructure, Transport and Regional Economics. 